\title{
Study on the relation between advance rate of single seam working face and gas drainage volume
}

\author{
XIAO Hanhan ${ }^{1,}$, , LI Weiguang ${ }^{1,} b^{*}$ \\ ${ }^{1}$ Institute of technology, Sichuan Normal University, Chengdu 610101, China \\ a505164149@qq.com, bwklhee51@163.com
}

\begin{abstract}
Keywords: advance rate; highly or low-located holes; gas drainage volume; regression analysis Abstract. In order to understand the relation between advance rate of single seam working face and gas drainage volume, the parameter of gas concentration, differential pressure, temperature, absolute pressure is measured in gas drainage pipelines after highly or low-located holes gas drainage method is adopted in 1306 working face to the strike. The relation between advance rate of single seam working face and gas drainage volume is put forward by means of regression analysis method. The study results show that gas drainage volume in 1306 working face is in turn rising slowly, rising quickly then slowly, and stabilizing totally with the stoping of working face. As the number of boreholes is continually increased, gas drainage volume in working face is not significantly increased when advance rate is more than $80 \mathrm{~m}$, and boreholes with low gas concentration and low mixing flow must be closed in time.
\end{abstract}

\section{Introduction}

With the advent of twenty-first century, the total amount of coal mine gas accidents has constantly declined in China, but there are still major gas-accident occur every now and then, which often happen in illegal productive coal mines [1-3]. Gas accident has become the first killer in coal mine production in view of statistics. The key to prevent gas accident is ventilation technology and gas drainage technology. However, many factors affect the effect of gas drainage in a working face, and the current research on gas drainage does not really combine coal mining and gas drainage to achieve the purpose of coal and gas simultaneous mining [4-6]. Based on the engineering background in 1306 working face on the strike in Shengli colliery in Sichuan province, the parameter of gas concentration, differential pressure, temperature, absolute pressure in 1306 intake roadway and in 1308 return roadway are measured for four months, finally the relation between advance rate of single seam working face and gas drainage volume is put forward by means of regression analysis method.

\section{Engineering background}

Designed mine capacity is $90 \mathrm{kt} / \mathrm{a}$ in Shengli colliery. Mine absolute gas emission rate is $20.17 \mathrm{~m}^{3} / \mathrm{min}$ in 2016, belonging to a gassy mine. Gas drainage system with permanent pump station is established, two type 2EB1-303 gas drainage pumps are installed, their motor power is 90kW.Gas drainage main pipe's diameter is $250 \mathrm{~mm}$, branch pipe's diameter $108 \mathrm{~mm} .1306$ working face is located in $-100 \mathrm{~m}$ level at the west wing of the third section in the tenth mining areas, 1306 roadway and 1308 roadway is respectively served as the intake roadway and return roadway of 1306 working face. The working face's strike length is $575 \mathrm{~m}$, inclined length is $100 \mathrm{~m}$, using longwall mining on the strike without coal pillar to mine. Hydraulic props are adopted to support roof, mining height is $0.7 \mathrm{~m}$, the maximum and minimum face width is respectively $3.8 \mathrm{~m}$ and $2.8 \mathrm{~m}$, goaf treatment method is partial stowing method. Mined K10d coal seam's thickness is $0.18 \mathrm{~m}$ to $0.52 \mathrm{~m}$, coal seam dip angle is $3^{\circ}$ to $5^{\circ}$. The up distance of $\mathrm{K} 10 \mathrm{~d}$ coal seam to $\mathrm{K} 10 \mathrm{~m}$ and $\mathrm{K} 10$ s coal seam is respectively $0.2 \mathrm{~m}$ to $0.35 \mathrm{~m}$ and 0.69 $\mathrm{m}$ to $1.0 \mathrm{~m}$, the down distance of $\mathrm{K} 10 \mathrm{~d}$ coal seam to $\mathrm{K} 11$ coal seam is $4 \mathrm{~m}$. Main roof of K10d coal seam is light gray fine sandstone, immediate roof is sandy shale and coal line, false roof is gray shale. Gas content in $\mathrm{K} 10 \mathrm{~d}$ coal seam is $7.39 \mathrm{~m}^{3} / \mathrm{t}$, K10d coal seam gas pressure is $0.71 \mathrm{MPa}$, gas 
permeability coefficient of $\mathrm{K} 10 \mathrm{~d}$ coal seam is 0.32 to $1.76 \mathrm{~m}^{2} /\left(\mathrm{MPa}^{2} \cdot \mathrm{d}^{1}\right)$, belonging to a moderate drainage coal seam.

\section{Gas drainage method in 1306 working face}

According to 1306 working face's workable coal seam and its adjacent unworkable coal seams, gas source, roof caving characteristics, et al, highly or low-located holes gas drainage method is adopted in 1306 working face to drain gas with pressure relief from workable K10d coal seam and unworkable $\mathrm{K} 10 \mathrm{~m}, \mathrm{~K} 10$ s and K11 coal seams within the scope of mining-induced. The first and second drilling fields are arranged in front of the coal body of 18,36 m from the working face's wall in 1308 return roadway, drilling fields spacing is $18 \mathrm{~m}$, and 2 drilling fields are always kept at both the front and the rear of the coal wall. The first drilling field is arranged in the rear of goaf of $12 \mathrm{~m}$ from the working face's wall in 1306 intake roadway, with drilling fields spacing every $18 \mathrm{~m}$. The working face's drilling fields layout is shown in Figure 1, drilling holes parameter is displayed in Table 1. Among them, No.1, 3 drilling hole is roof drilling holes in 1306 intake roadway, and No.2, 4 floor drilling holes. No.2, 4, 6 drilling hole is floor drilling holes in 1308 return roadway, and No.1, 3, 5 roof drilling holes [7].

Table 1 Drilling holes parameter in 1306 working face

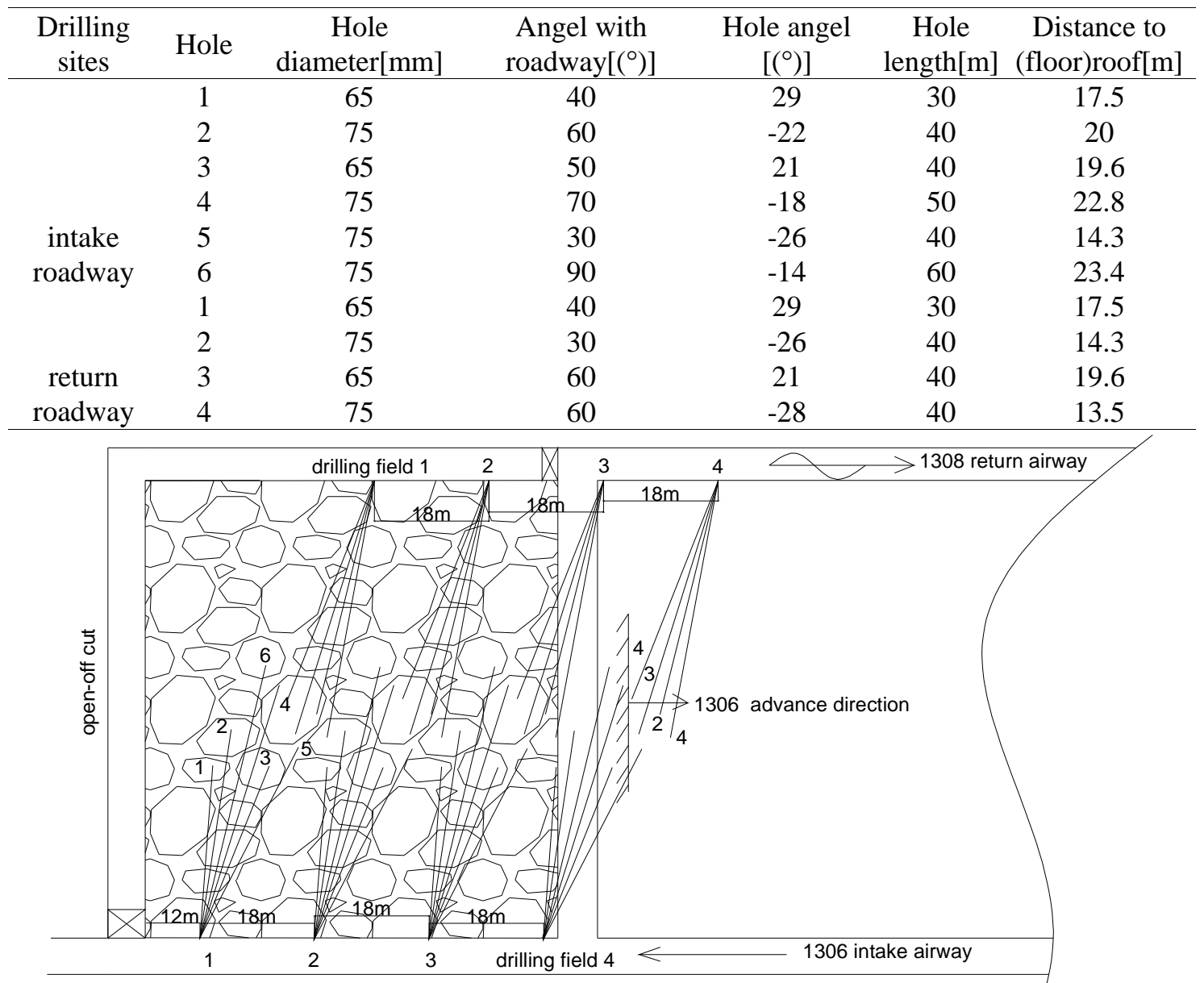

Figure 1. Layout sketch of drilling fields and drilling holes in 1306 working face

\section{The relation between advance rate of single seam working face and gas drainage volume}

Regression analysis method is used to analyze the measured data between the intake roadway's gas drainage volume, the return roadway's gas drainage volume, the working face's gas drainage volume and advance rate shown in Figure 2 [8]. The relation between the intake roadway's gas drainage 
volume, the return roadway's gas drainage volume, the working face's gas drainage volume and advance rate is put forward.

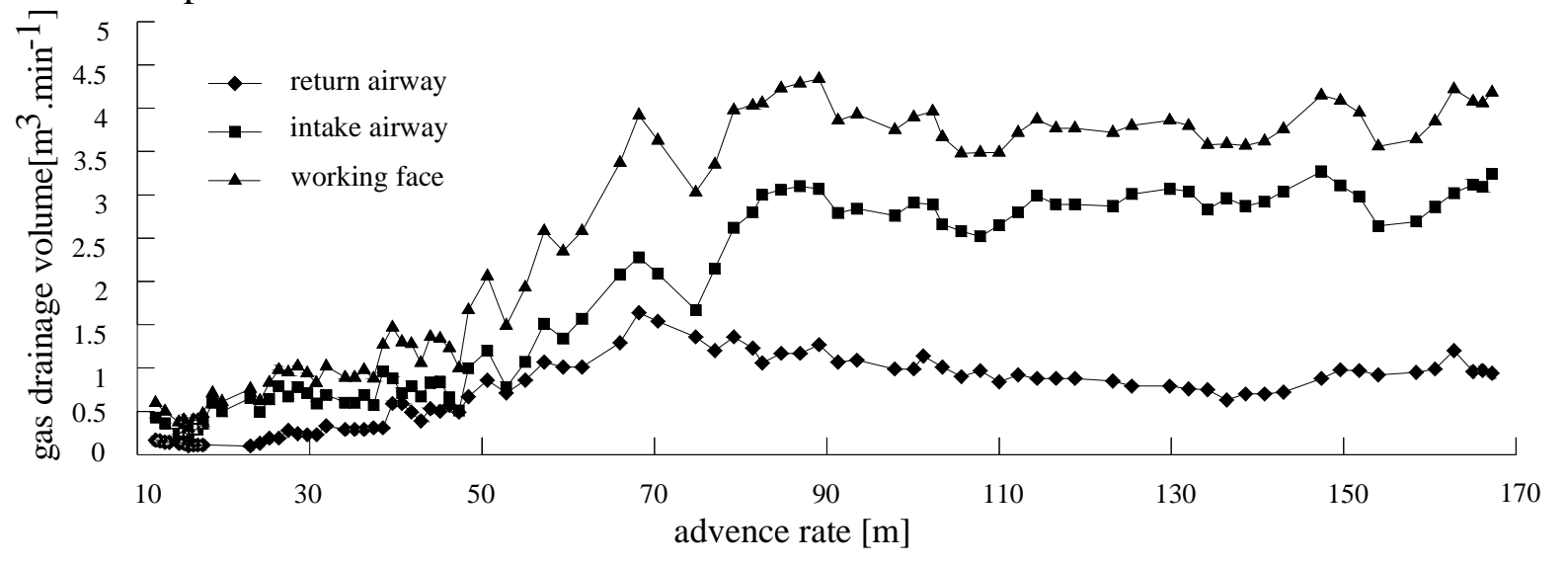

Figure 2. The relation between advance rate and gas drainage volume in 1306 working face

With the stoping of working face, when advance rate is $12.1 \mathrm{~m}$ to $50.6 \mathrm{~m}$, gas drainage volume in 1306 intake roadway is slowly increasing to $1.2 \mathrm{~m} 3 / \mathrm{min}$. When advance rate is $50.6 \mathrm{~m}$ to $84.7 \mathrm{~m}$, gas drainage volume in 1306 intake roadway is sharply rising from $1.2 \mathrm{~m}^{3} / \mathrm{min}$ to the maximum 3.1 $\mathrm{m}^{3} / \mathrm{min}$. When advance rate is $84.7 \mathrm{~m}$ to $167.2 \mathrm{~m}$, gas drainage volume in 1306 intake roadway is around $3 \mathrm{~m}^{3} / \mathrm{min}$. The relationship between the working face's advance rate $\mathrm{x}(\mathrm{m})$ and gas drainage volume in 1306 intake roadway $\mathrm{Q}_{1}\left(\mathrm{~m}^{3} / \mathrm{min}\right)$ is shown in equation 1.

$$
Q_{1}=-0.0002 x^{2}+0.0534 x-0.7659, R^{2}=0.9211
$$

Where, $\mathrm{R}^{2}$ is the determination coefficient of regression equation.

With the stoping of working face, when advance rate is $12.1 \mathrm{~m}$ to $68.2 \mathrm{~m}$, gas drainage volume in 1308 return roadway is slowly increasing up to the maximum $1.64 \mathrm{~m}^{3} / \mathrm{min}$. When advance rate is 68.2 $\mathrm{m}$ to $167.2 \mathrm{~m}$, gas drainage volume in 1308 return roadway is slowly declined from $1.64 \mathrm{~m} / \mathrm{min}$, then laxly increasing to about $1 \mathrm{~m}^{3} / \mathrm{min}$. The relationship between the working face's advance rate $\mathrm{x}(\mathrm{m})$ and gas drainage volume in 1308 return roadway $\mathrm{Q}_{2}\left(\mathrm{~m}^{3} / \mathrm{min}\right)$ is shown in equation 2.

$$
Q=\left\{\begin{array}{l}
0.0004 x^{2}-0.0102 x+0.1624, R^{2}=0.9654 \\
0.0002 x^{2}-0.0477 x+3.9521, R^{2}=0.8745
\end{array}\right.
$$

Gas drainage volume in 1306 working face is termed as the sum of gas drainage volume in 1306 intake roadway and gas drainage volume in 1308 return roadway. With the stoping of working face, when advance rate is $12.1 \mathrm{~m}$ to $50.6 \mathrm{~m}$, gas drainage volume in 1306 working face is slowly increasing to $2.06 \mathrm{~m}^{3} / \mathrm{min}$. When advance rate is $50 \mathrm{~m}$ to $89.1 \mathrm{~m}$, gas drainage volume in 1306 working face is rising from $2.06 \mathrm{~m}^{3} / \mathrm{min}$ to the maximum $4.34 \mathrm{~m}^{3} / \mathrm{min}$. When advance rate is $89.1 \mathrm{~m}$ to $167.2 \mathrm{~m}$, gas drainage volume fluctuates in the level of $4 \mathrm{~m}^{3} / \mathrm{min}$. The relation between the working face's advance rate $\mathrm{x}(\mathrm{m})$ and gas drainage volume in 1306 working face $\mathrm{Q}\left(\mathrm{m}^{3} / \mathrm{min}\right)$ is shown in equation 3 .

$$
Q=-0.0003 x^{2}+0.0785 x-1.0045, R^{2}=0.9074
$$

The average gas drainage volume in 1306 intake roadway and in 1308 return roadway is respectively $1.5638 \mathrm{~m}^{3} / \mathrm{min}$ and $0.6296 \mathrm{~m}^{3} / \mathrm{min}$, gas drainage volume in 1306 intake roadway is 2.48 time more than that in 1308 return roadway. The reason is that there are only 4 drilling fields in 1308 return roadway when 1306 working face is advanced. But a new drilling field is arranged in 1306 intake roadway every $18 \mathrm{~m}$, the number of drilling fields is naturally increased.

Gas drainage volume in 1306 working face is respectively increasing slowly, rising rapidly then slowly, and stabilizing totally with the stoping of working face. When the working face's advance rate is more than $80 \mathrm{~m}$, gas drainage volume in 1306 working face is not significantly increased as the 
number of drilling holes is continuously increased, that is, gas drainage volume is generally stabilized on about $4 \mathrm{~m}^{3} / \mathrm{min}$.

\section{Conclusion}

Gas drainage volume in 1306 working face is respectively rising slowly, rising quickly then slowly, and stabilizing totally with the stoping of working face.

Under certain conditions of mine gas drainage ability, as the number of boreholes is continually increased, gas drainage volume in 1306 working face is generally stabilized on about $4 \mathrm{~m}^{3} / \mathrm{min}$ when advance rate is more than $80 \mathrm{~m}$, and boreholes with low gas concentration and low mixing flow must be closed in time.

\section{References}

[1] H.P. Xie, H.W. Zhou, J.H. Xue and F. Gao: Journal of China Coal Society, Vol. 39 (2014) No.8, p.1391-1397. (In Chinese)

[2] L. Yuan, J.H. Xue, N. Zhang and P. Lu: Coal Science and Technology, Vol. 41 (2013) No.9, p. 6-11. (In Chinese)

[3] Y.M.Zhu: Statistical Analysis of Coal Mine Safety Accidents (MS., Liaoning Technical University, China 2012). (In Chinese)

[4] W.G. He: Practical Technology for Mine Gas Control, Revised (Beijing: Coal Industry Press, China2011). (In Chinese)

[5] J.J.Guo, X.Y.Cheng: Coal Technology, Vol. 35 (2016) No.8, p. 153-154. (In Chinese)

[6] L. Yuan, H. Guo, B.T. Shen, Q.D. Qu and J.H. Xue: Journal of China Coal Society, Vol. 36 (2011) No.3, p. 357-365. (In Chinese)

[7] H.J. He: China Coal, Vol. 43 (2017) No.3, p. 134-139. (In Chinese)

[8] C. Li: Research on Gas Drainage Technology of Shengli Coal Mine (MS.,Sichuan Normal University, China 2016). (In Chinese) 